\title{
KEY FEATURES AND EDUCATIONAL USES OF THE DESCRIBE MENU IN R-INSTAT
}

\author{
Maxwell Fundi ${ }^{1}$, Danny Parsons ${ }^{2}$, Lily Clements ${ }^{3}$, Steven Ndungu ${ }^{1}$, Alex Sananka ${ }^{1}$, David Stern ${ }^{4}$, \\ and Roger Stern ${ }^{3,4}$ \\ ${ }^{1}$ African Maths Initiative \\ ${ }^{2}$ Supporting African Maths Initiatives \\ ${ }^{3}$ Statistics for Sustainable Development \\ ${ }^{4}$ University of Reading \\ maxwell@africanmathsinitiative.net
}

This poster focusses on the describe menu of R-Instat; in particular, features relating to data exploration. The exploration of data is fundamentally important for anyone working with data, yet it receives relatively little importance in many statistics courses. The poster illustrates some key aspects of tables and graphs in R-Instat and how they can be used to quickly get an overview of data. It shows how descriptive analyses are made into an easy and natural process, both to teach and to learn. We illustrate a wide variety of graphs that use ggplot2 in R, how to produce tables that are eye-catching and useful, and the similarities between tables and graphs. We can have a table of graphs or graphs where some of the cells have a table. Particular attention will be drawn to the value of a true problem based approach, where students start with a problem and some data and are free to use any appropriate analytic methods. The key to this approach is to have data which is rich enough that a combination of approaches yields more insights than any single analysis. Analyzing data can be fun! 